\title{
Removal of Ammonia Nitrogen from Wastewater Using Modified Activated Sludge
}

\author{
Chen Yunnen*, Xiong Changshi, Nie Jinxia \\ School of Resource and Environmental Engineering, Jiangxi University of Science and Technology, \\ Jiangxi Key Laboratory of Mining \& Metallurgy Environmental Pollution Control \\ Hongqi Ave. 86, Ganzhou Jiangxi 341000, P.R. China
}

Received: 9 March 2015

Accepted: 1 December 2015

\begin{abstract}
The removal of medium-low $\mathrm{N}_{-} \mathrm{NH}_{4}$ on activated sludge modified by ferric hydroxide suspension (FHMAS) in batch studies was conducted as a function of $\mathrm{pH}$, concentration of modifier, contact time, and initial concentration. The kinetics study showed that the sorption behavior fit well the pseudo second-order equation. An adsorption isotherms study indicated that FHMAS had a higher adsorption capacity for $\mathrm{N}_{-} \mathrm{NH}_{4}$ than other adsorbents. The mechanism of removal of $\mathrm{N}^{-\mathrm{NH}_{4}}$ by FHMAS was coexistence of adsorption and cation exchange. Initial $\mathrm{N}-\mathrm{NH}_{4}$ concentration being $116 \mathrm{mg} / \mathrm{l}$ in metallurgical wastewater was reduced to $11 \mathrm{mg} / \mathrm{l}$ after adsorption treatment.
\end{abstract}

Keywords: ammonium-nitrogen $\left(\mathrm{N}-\mathrm{NH}_{4}\right)$ removal, activated sludge modified by ferric hydroxide (FHMAS), cation exchange, adsorption

\section{Introduction}

Eutrophication of surface water is primarily contributed by nitrogen and phosphorus contamination from industry wastewater, farmland fertilization, and municipal sewage, which has been a common environmental issue in many countries [1]. These nutrients cause diverse problems such as toxic algal blooms, loss of oxygen, fish kills, loss of biodiversity, loss of aquatic plant beds and coral reefs, and other problems.

Great efforts have been aimed at the removal of N-NH from wastewater. Traditional methods include ammoniastripping [2], chemical precipitation [3], biological denitrification [4], dry-ice [5], and so on. Ammonia stripping makes use of a stripping tower, consumes much

*e-mail: cyn70yellow@gmail.com energy, and is only suitable for treating high $\mathrm{N}-\mathrm{NH}_{4}$ concentrations. Chemical precipitation needs additional reagents that can introduce new pollutants to water bodies. Biological denitrification is the most common process in the

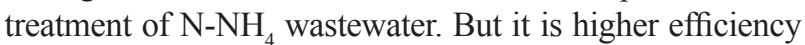
for the removal of low $\mathrm{N}-\mathrm{NH}_{4}$ concentration due to the requirement of an appropriate $\mathrm{C} / \mathrm{N}$ ratio [6] and need for a long reaction time. It is inefficient, though, for the traditional ways to quickly treat medium-low $\mathrm{N}_{-} \mathrm{NH}_{4}$ from wastewater. In recent years considerable attention has been aimed at the study of heavy metals removal from solution by adsorption using wastes, including fruit peels, straw, coconut coir, and so on [7-9]. Generally, the sorption capacities of crude byproducts are low. To improve the adsorption capacity of these by-products, chemical modification has been used.

Surplus activated sludge is the by-product of sewage treated by the activated sludge process. Every year a large amount of activated sludge from a sewage plant 
is produced. In this study, activated sludge was used as the biosorbents to remove medium-low $\mathrm{N}_{-} \mathrm{NH}_{4}$ from aqueous solution and wastewater. Because of its sorptional nature, ferric compounds often apply to the treatment of wastewater with heavy metals [10-11]. The objectives are to identify the $\mathrm{NH}_{4}^{+}$ion uptake capacity of the activated sludge modified by ferric hydroxide (FHMAS) to determine the kinetics, and assess the effects of $\mathrm{pH}$, concentration of modifier, contact time, and $\mathrm{N}_{-} \mathrm{NH}_{4}$ initial concentration on the removal. Then the adsorption isotherm of $\mathrm{NH}_{4}^{+}$ is obtained, which contains the basic information for exploiting sludge as a water treatment agent.

\section{Material and Methods}

\section{Adsorbate}

Ammonium chloride (99.5\%, analytical reagent, Tianjin Kermel Chemical Reagent Development Center, China) was used as the source of N-NH . Deionized water was used for the preparation of solutions. All other reagents such as ferric chloride, sodium hydroxide $(\mathrm{NaOH})$, and hydrochloric acid $(\mathrm{HCl})$ were analytical grade. Real $\mathrm{N}-\mathrm{NH}_{4}$ wastewater was obtained from a Metallurgical Plant of Ganzhou, Jiangxi, China.

\section{Adsorbent}

The activated sludge was obtained from a wastewater treatment plant of Ganzhou City, P. R. China. After being washed many times in distilled water, the sludge was dried at $110^{\circ} \mathrm{C}$ and sieved through a $245 \mu \mathrm{m}$ sieve and stored dry until use, labeled as original activated sludge (OAS).

Adding $\mathrm{NaOH}$ solution to a certain concentration $(0.05 \sim 0.30 \mathrm{~mol} / \mathrm{l})$ of ferric chloride solution, ferric hydroxide suspension was produced. With the ratio of $1 \mathrm{~g}$ OAS to $10 \mathrm{ml}$ ferric hydroxide, suspensions were mixed uniformly and placed in an oven at $60^{\circ} \mathrm{C}$ for $12 \mathrm{~h}$, and the suspension liquid was filtered and washing many times by distilled water until the effluent was cleared up. The filtered solid was dried at $110^{\circ} \mathrm{C}$ and stored for dry until use and labeled as activated sludge modified by ferric hydroxide (FHMAS).

\section{Batch Experimental Procedures}

The removal of $\mathrm{N}_{-} \mathrm{NH}_{4}$ with FHMAS was performed in batch experiments. Prior to experiments, the $\mathrm{pH}$ value of $\mathrm{N}_{-} \mathrm{NH}_{4}$ solution was changed from 3 to 10 , with 0.1 $\mathrm{mol} / \mathrm{l} \mathrm{NaOH}$ or $\mathrm{HCl}$ solution. During the removal process, $0.3 \mathrm{~g}$ FHMAS or OAS was suspended in $100 \mathrm{ml}$ wastewater containing $\mathrm{N}-\mathrm{NH}_{4}(100 \pm 5 \mathrm{mg} / \mathrm{l})$. The mixture was agitated on a gyratory shaker at $250 \mathrm{rpm}$ by $20 \mathrm{~min}$. At the end of the experiment the suspension liquid was decanted and filtered through a $0.45 \mu \mathrm{m}$ cellulose acetate filter and the supernatant was analyzed. Controls were also performed with no adsorbent to compare the efficiency of $\mathrm{N}-\mathrm{NH}_{4}$ removal with FHMAS and OAS.
All other experiments were conducted at $\mathrm{pH}$ 8. As for the factor of modifier concentration, samples were collected after 20 min contact with FHMAS and efficiency of $\mathrm{N}-\mathrm{NH}_{4}$ removal was analyzed. Based on the same ferric concentration, a different volume of ferric hydroxide suspension but no FHMAS added was also performed to compare the $\mathrm{N}_{-} \mathrm{NH}_{4}$ removal with FHMAS. At the experimental process, the ferric ion concentration in solution also was analyzed.

In the contact time experiment, samples were withdrawn at pre-determined intervals and efficiency of $\mathrm{N}-\mathrm{NH}_{4}$ removal was analyzed. The percent efficiency of removal of $\mathrm{N}_{-} \mathrm{NH}_{4}$ in solution was calculated by the use of the following equation:

$$
\eta=\frac{C_{0}-C_{t}}{C_{0}} \times 100
$$

...where $C_{0}$ is $\mathrm{N}^{-\mathrm{NH}_{4}}$ concentrations an the start of process $(\mathrm{mg} / \mathrm{l}), C_{t}$ is N-NH $\mathrm{N}_{4}$ concentrations after time $\mathrm{t}(\mathrm{mg} / \mathrm{l})$, and $t$ is time of process.

At the mentioned optimum conditions, the effects of initial $\mathrm{N}_{-} \mathrm{NH}_{4}$ concentration $(20-250 \mathrm{mg} / \mathrm{l})$ on the sorption of $\mathrm{N}^{-\mathrm{NH}_{4}}$ was studied under the aspects of sorption isotherms. The amount of $\mathrm{N}-\mathrm{NH}_{4}$ adsorbed per adsorbent mass was calculated by the use of the following equation:

$$
q_{t}=\frac{\left(C_{0}-C_{t}\right) V}{m}
$$

... where $q_{t}$ is the amount of $\mathrm{N}-\mathrm{NH}_{4}$ adsorbed on sludge at time $t(\mathrm{mg} / \mathrm{g}), V$ is the volume of solution (1), and $m$ is the adsorbent mass $(\mathrm{g})$.

All experiments were fulfilled at room temperature $(293 \pm 1 \mathrm{~K})$. Each experiment was run in triplicate and mean values were calculated.

\section{Analysis and Measurements}

$\mathrm{N}-\mathrm{NH}_{4}$ was measured by WT-1 portable apparatus of $\mathrm{N}^{-N_{4}}$ (Wuhan Water Environmental Protection Company, China), which was based on the standard method [12]. $\mathrm{Fe}^{3+}$ was determined based on the phenanthroline spectrophotometric method. $\mathrm{pH}$ was measured with a pH meter (pHS-25, Shanghai Leici Instrument Factory, China).

\section{Results and Discussion}

\section{Effect of $\mathrm{pH}$ on $\mathrm{N}_{-} \mathrm{NH}_{4}$ Removal}

Ammonium is always a pH-dependent balance between soluble ammonium ion $\mathrm{NH}_{4}^{+}$and dissolved molecular ammonia $\mathrm{NH}_{3}$ in wastewater [13]. In acidic and neutral media, $\mathrm{N}_{-} \mathrm{NH}_{4}$ is presented as $\mathrm{NH}_{4}^{+}$. In basic solution, non-volatile $\mathrm{NH}_{4}^{+}$is converted to $\mathrm{NH}_{3}$. High pH favors ammonia volatilization by moving the equilibrium 
between $\mathrm{NH}_{3}$ and $\mathrm{NH}_{4}^{+}$to molecular ammonia, as shown in equation (3). In this study the $\mathrm{pH}$ from 3 to 10 was changed.

$$
\mathrm{NH}_{4}^{+}+\mathrm{OH}^{-} \Leftrightarrow \mathrm{NH}_{3}+\mathrm{H}_{2} \mathrm{O}
$$

In order to determine the desired $\mathrm{pH}$ for adsorption of $\mathrm{N}-\mathrm{NH}_{4}$ over FHMAS, the uptake of $\mathrm{N}_{-} \mathrm{NH}_{4}$ as a function of hydrogen ion concentration was studied, as Fig. 1 showed. From Fig. 1 it can be seen that all three curves have the same trend, namely that inflection points appeared at $\mathrm{pH} 8$. The net sorption removal of $\mathrm{N}_{-} \mathrm{NH}_{4}$ by OAS was $9.1,19.1$, $23.9,30.1,40.3,44.3,42.1$, and $40.6 \%$ after deducting results of the controls group at $\mathrm{pH} 3,4,5,6,7,8$, 9, and 10 , respectively. The net sorption effect by FHMAS was $22.3,32.6,39.7,47.9,60.3,68,66.1$, and $63.8 \%$ at $\mathrm{pH} 3$, $4,5,6,7,8,9$, and 10 , respectively.

Under three conditions the removal of $\mathrm{N}_{-} \mathrm{NH}_{4}$ increased with $\mathrm{pH}$ of solution increasing. Ammonium chloride solution is a strong acid with weak base salt. At low $\mathrm{pH}$, the surface ligands are closely associated with the hydronium ions $\left(\mathrm{H}_{3} \mathrm{O}^{+}\right)$and restricted the approach of $\mathrm{NH}_{4}^{+}$cation as a result of the repulsive force. Moreover, the ferric oxide layer on the surface of FHMAS was hydroxylated and positively charged at acidic water environment, which went against $\mathrm{N}-\mathrm{NH}_{4}$ adsorption.

It was observed that the presence of $\mathrm{Fe}^{3+}$ in solution was detected after contacting ammonium chloride solution with FHMAS, which inferred that ion-exchange between $\mathrm{N}-\mathrm{NH}_{4}$ and $\mathrm{Fe}^{3+}$ might exist.

All subsequent experiments were conducted with $\mathrm{pH} 8$.

\section{Effect of Concentration of Modifier on $\mathrm{N}_{-} \mathrm{NH}_{4}$ Removal}

The effects of concentration of modifier and ferric hydroxide suspension on the efficiency of $\mathrm{N}^{-\mathrm{NH}_{4}}$ removal

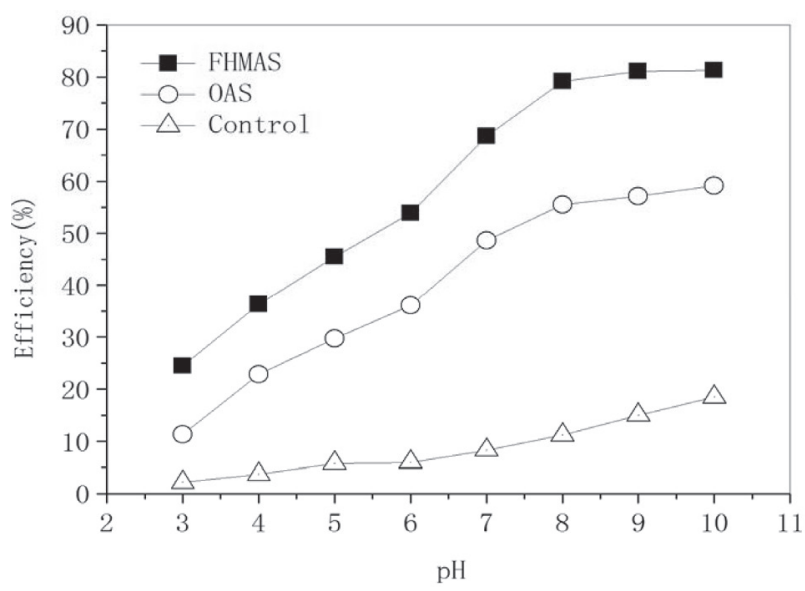

Fig. 1. Effect of $\mathrm{pH}$ on $\mathrm{N}-\mathrm{NH}_{4}$ removal. Initial $\mathrm{N}-\mathrm{NH}_{4}$ concentration was $99.45 \mathrm{mg} / \mathrm{l}$, concentration of modifier $0.10 \mathrm{~mol} / 1$, contact time $20 \mathrm{~min}$, sorbent dose $3 \mathrm{~g} / \mathrm{l}$. are shown in Fig. 2. The two curves in Fig. 2 show that the efficiency of $\mathrm{N}_{-} \mathrm{NH}_{4}$ removal onto FHMAS was higher than that of ferric hydroxide suspension. The effect of removal always increases with the $\mathrm{Fe}^{3+}$ concentration increasing for FHMAS, indicated that perhaps increasing adsorption sites can increase the efficiency of $\mathrm{N}^{-\mathrm{NH}_{4}}$ removal by adsorption.

After the experimental process, the analyzed $\mathrm{Fe}^{3+}$ concentration in solution showed that the content of $\mathrm{Fe}^{3+}$ increased with $\mathrm{N}^{-\mathrm{NH}_{4}}$ efficiency of removal increasing by FHMAS, but $\mathrm{Fe}^{3+}$ concentration was almost zero by ferric hydroxide suspension, which inferred the existence of cation exchange in the experimental process with FHMAS. Analysis of the data showed that the number of removed $\mathrm{N}-\mathrm{NH}_{4}$ was more than that of $\mathrm{Fe}^{3+}$ in solution, which meant that cation exchange and adsorption are taking place at the same time.

Fig. 2 also showed that the efficiency of removal of $\mathrm{N}-\mathrm{NH}_{4}$ by FHMAS was first increased and then decreased with the concentration of increasing modifier. Maybe a small amount of ferric hydroxide can enhance the cation exchange capacity with $\mathrm{NH}_{4}{ }^{+}$. The excess ferric hydroxide may be part of the sludge pore blockage and lead to the decline of FHMAS adsorption capacity for $\mathrm{N}_{-} \mathrm{NH}_{4}$.

All subsequent experiments were conducted with 0.15 $\mathrm{mol} / \mathrm{l}$ ferric hydroxide suspension.

\section{Kinetics Study}

The efficiency of removal rate of $\mathrm{N}^{-\mathrm{NH}_{4}}$ by FHMAS is shown in Fig. 3. The sorption process was rapid in less than $20 \mathrm{~min}$ and reached a plateau of some $87 \%$ in $30 \mathrm{~min}$.

Various sorption kinetic models have been used to describe the removal of metals. The Lagergren first-order kinetic process has been used for reversible reaction with an equilibrium between liquid and solid phases. The rate equation for the reaction may be represented by the following expression:

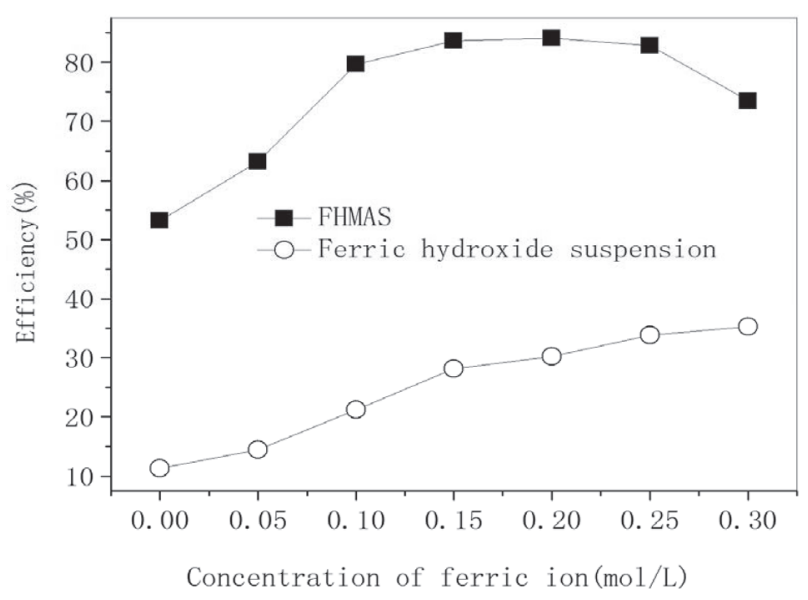

Fig. 2. Effect of concentration of modifier on $\mathrm{N}_{-} \mathrm{NH}_{4}$ removal. Initial $\mathrm{N}^{-\mathrm{NH}_{4}}$ concentration was $101.83 \mathrm{mg} / \mathrm{l}$, $\mathrm{pH} 8$, contact time $20 \mathrm{~min}$, adsorbent dose $3 \mathrm{~g} / \mathrm{l}$. 


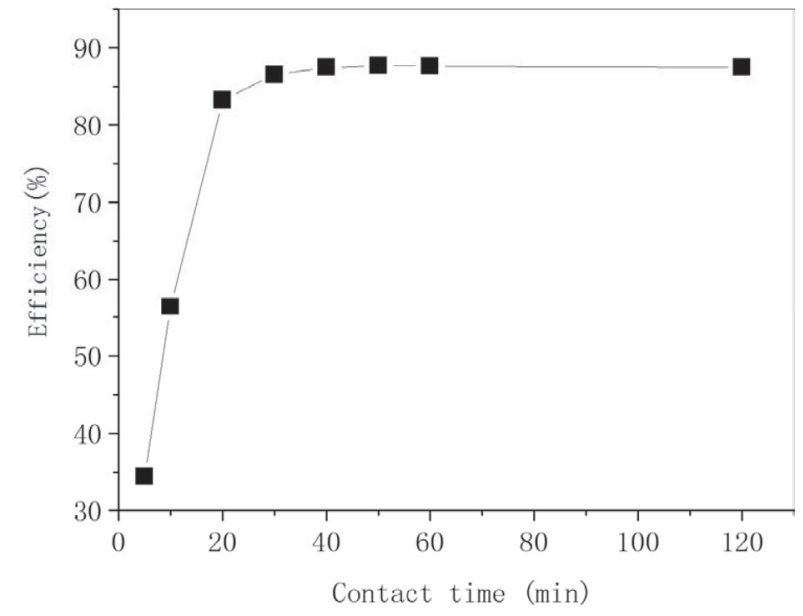

Fig. 3. Effect of contact time on $\mathrm{N}_{-} \mathrm{NH}_{4}$ removal. Initial N-NH concentration was $103.38 \mathrm{mg} / \mathrm{l}, \mathrm{pH} 8$, concentration of modifier $0.15 \mathrm{~mol} / \mathrm{l}$, adsorbent dose $3 \mathrm{~g} / \mathrm{l}$.

$$
\log \left(q_{e}-q_{\mathrm{t}}\right)=\log q_{e}-\frac{k_{1}}{2.303} t
$$

... where $t$ is contact time (min), $q_{t}$ is quantities of $\mathrm{N}^{-\mathrm{NH}_{4}}$ adsorbed at time $t(\mathrm{mg} / \mathrm{g}), q_{e}$ is quantities of $\mathrm{N}^{-\mathrm{NH}_{4}}$ adsorbed at equilibrium $(\mathrm{mg} / \mathrm{g})$, and $k_{1}$ is sorption rate constant.

From Eq. (4), a plot of $\lg \left(q_{e}-q_{t}\right)$ versus $t$ should give a straight line to confirm the applicability of the first-order kinetic model (Fig. 4), in which the correlation coefficient $\left(R^{2}\right)$ was 0.76 .

However, a pseudo second-order kinetic model has been considered to be the most appropriate over the past few years [14]. As a result, if a pseudo second-order equation is adequate, the rate equation for the reaction may be represented by the following expression:

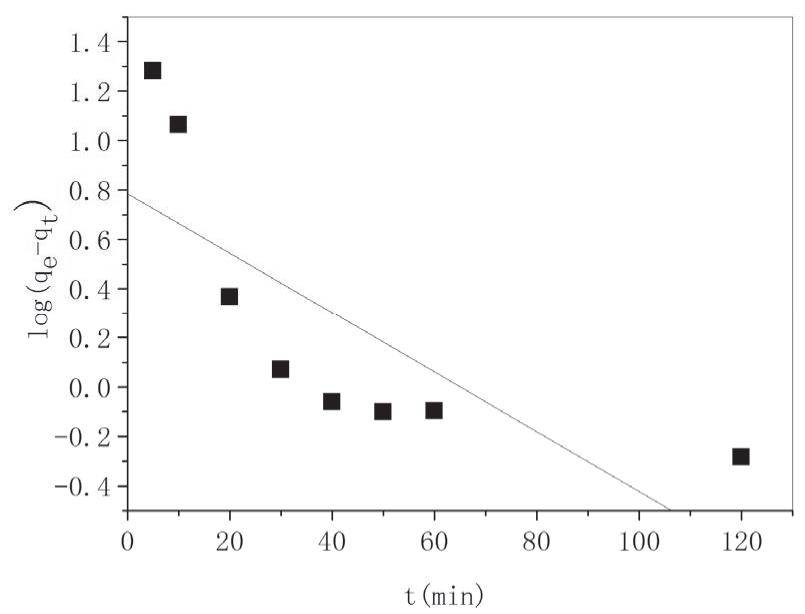

Fig. 4. Lagergren first-order Sorptional kinetics of $\mathrm{N}^{-\mathrm{NH}_{4}}$ by FHMAS.

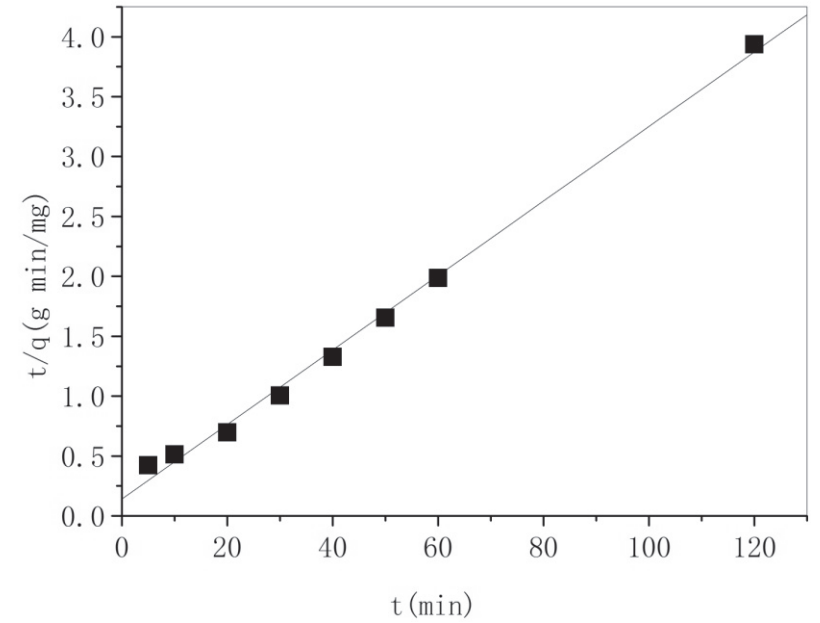

Fig. 5. Pseudo second-order sorptional kinetics of $\mathrm{N}^{-\mathrm{NH}_{4}}$ by FHMAS.

$$
\frac{t}{q_{t}}=\frac{1}{k_{2}}+\frac{t}{q_{e}}
$$

...where $k_{2}$ is sorption rate constant $(\mathrm{mg} /(\mathrm{g} \cdot \mathrm{min}))$. From Eq. (5), a plot of $t / q_{t}$ versus $t$ should give a straight line to confirm the applicability of the second-order kinetic model (Fig. 5).

Table 1 contains the sorptional kinetics parameters of $\mathrm{N}-\mathrm{NH}_{4}$ by FHMAS. From the correlation coefficient $\left(R^{2}\right)$ of two lines it can been seen that the pseudo second-order kinetic $\left(R^{2}=0.99\right)$ was more fitted than that of Lagergren first-order kinetic $\left(R^{2}=0.76\right)$ for the sorption process.

\section{Adsorption Isotherms}

Langmuir adsorption isotherm model was tried to fit to the experimental adsorption data by linear estimation based on least-square method and the equation shown below:

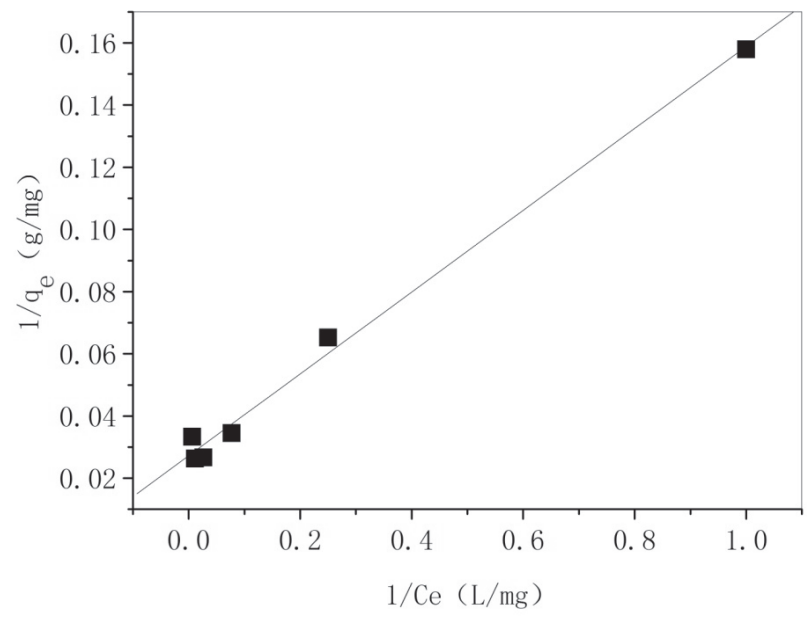

Fig. 6. Langmuir adsorption model of $\mathrm{N}^{-\mathrm{NH}_{4}}$ by FHMAS. 
Table 1. Sorptional kinetics parameters of $\mathrm{N}_{-} \mathrm{NH}_{4}$ by FHMAS.

\begin{tabular}{|c|c|c|c|}
\hline Sorptional kinetics & Fitted equation & Sorption rate constant & Correlation coefficient \\
\hline Lagergren first-order kinetic & $\log \left(6.10-q_{t}\right)=\log 6.10-\frac{0.027}{2.303} t$ & 0.02 & 0.76 \\
\hline $\begin{array}{c}\text { Pseudo second-order } \\
\text { kinetic }\end{array}$ & $\frac{t}{q_{t}}=\frac{1}{7.10}-\frac{t}{32.15}$ & $7.10 \mathrm{mg} /(\mathrm{g} \cdot \mathrm{min})$ & 0.99 \\
\hline
\end{tabular}

Table 2. Langmuir and Dubini-Radushkevich isotherm parameters estimated with the equilibrium adsorption data for $\mathrm{N}_{-} \mathrm{NH}_{4}$ by $\mathrm{FHMAS}$ at $20^{\circ} \mathrm{C}$.

\begin{tabular}{|c|c|c|c|c|c|c|}
\hline \multicolumn{3}{|c|}{ Langmuir } & \multicolumn{5}{c|}{ Dubini-Radushkevich } \\
\hline $\begin{array}{c}q_{m} \\
(\mathrm{mg} / \mathrm{g})\end{array}$ & $\begin{array}{c}B \\
(1 / \mathrm{mg})\end{array}$ & $R^{2}$ & $\begin{array}{c}q_{m} \\
(\mathrm{mg} / \mathrm{g})\end{array}$ & $\begin{array}{c}\beta^{*} 10^{9} \\
\left(\mathrm{~mol}^{2} / \mathrm{J}^{2}\right)\end{array}$ & $\begin{array}{c}E \\
(\mathrm{~kJ} / \mathrm{mol})\end{array}$ & $R^{2}$ \\
\hline 32.71 & 0.18 & 0.99 & 29.96 & 5.63 & 9.42 & 0.92 \\
\hline
\end{tabular}

$$
\frac{1}{q_{e}}=\frac{1}{b q_{\max } C_{e}}+\frac{1}{q_{\max }}
$$

...where $C_{e}$ is equilibrium concentration $(\mathrm{mg} / \mathrm{l}), q_{\max }$ is maximum adsorption capacity $(\mathrm{mg} / \mathrm{g})$, and $b$ is relative energy of sorption ( $1 / \mathrm{mg})$. The value of $q_{\max }$ and $b$ were calculated from the intercept and slope of the lines in diagram of $\left(1 / q_{e}\right)$ versus $\left(1 / C_{e}\right)$. As shown in Fig. 6, the regression correlation coefficients of plot of $\left(1 / q_{e}\right)$ versus $\left(1 / C_{e}\right)$ gave a straight line for $\mathrm{N}^{-\mathrm{NH}_{4}}$ adsorption by FHMAS.

The Langmuir model fit well the experimental data based on the obtained determination coefficients $\left(R^{2}=0.997\right)$ and isotherm parameters shown in Table 2 .

The maximum adsorption capacity $\left(q_{\max }\right)$ of FHMAS, obtained in this research for $\mathrm{N}-\mathrm{NH}_{4}$, can be compared with other adsorbents' $\mathrm{N}-\mathrm{NH}_{4}$ uptake as shown in Table 3. It can be observed that the FHMAS had adsorption capacities for $\mathrm{N}-\mathrm{NH}_{4}$ of 7.43 times higher than that of the bentonite [15].

In addition, the Dubini-Radushkevich isotherm model (Eq. 7) was tried to fit to the experimental adsorption data by lineal estimation based on the least-square method:

Table 3. Comparison of $q_{\max }$ of $\mathrm{N}-\mathrm{NH}_{4}$ on different adsorbents.

\begin{tabular}{|c|c|c|}
\hline Adsorbent & $q_{\max }(\mathrm{mg} / \mathrm{g})$ & References \\
\hline Clinoptilolite & 4.4 & 15 \\
\hline Artificial Zeoliteand & 26.9 & 16 \\
\hline Kaolin & 4.3 & 17 \\
\hline Na-based bentonite & 3.0 & 18 \\
\hline Rare earth absorbent & 6.5 & 19 \\
\hline Wheat shell & 8.1 & 20 \\
\hline FHMAS & 32.7 & This study \\
\hline
\end{tabular}

$$
q=q_{m} e^{-\beta \varepsilon^{2}}
$$

...where $q_{m}$ is Dubinin-Radushkevich monolayer capacity $(\mathrm{mg} / \mathrm{g}), \beta$ is constant related to adsorption energy $\left(\mathrm{mol}^{2} /\right.$ $\left.\mathrm{J}^{2}\right), \varepsilon$ is Polanyi potential $(\mathrm{J} / \mathrm{mol})$ related to equilibrium concentration $C_{e}$.

$$
\varepsilon=R T \ln \left(1+\frac{1}{C_{e}}\right)
$$

...where $R$ is gas constant $(8.314 \mathrm{~J} / \mathrm{mol})$ and $T$ is absolute temperature.

The constant $\beta$ is related to the mean free energy of adsorption per mol of the adsorbate $(E, \mathrm{~kJ} / \mathrm{mol})$ when it is transferred to the surface of the solid from the solution, and $E$ can be estimated as follows:

$$
E=\frac{1}{\sqrt{2 \beta}}
$$

Table 2 shows the Dubini-Radushkevich isotherm parameters for $\mathrm{N}_{-} \mathrm{NH}_{4}$ by FHMAS. The $q_{m}$ value shows less adsorption capacity in comparison to Langmuir isotherm. Moreover, the free energy of adsorption values $(4-40 \mathrm{~kJ} / \mathrm{mol})$ suggests that physical the adsorption process occurs at the adsorbent surface [16].

\section{Treatment of Metallurgical Wastewater}

High concentrations of $\mathrm{N}-\mathrm{NH}_{4}$ are commonly present in industrial wastewater such as metallurgical, tannery, textile, landfill leachate, and fertilizer wastewater [1719]. The real wastewater used in this study was obtained from a metallurgical plant in Ganzhou City, P. R. China. The metallurgical wastewater quality before and after treatment by FHMAS is listed in Table 4. 
Table 4 . Water quality before and after treatment of metallurgical wastewater by FHMAS.

\begin{tabular}{|c|c|c|c|c|c|c|c|c|}
\hline Items & $\mathrm{pH}$ & $\begin{array}{c}\mathrm{COD} \\
(\mathrm{mg} / \mathrm{l})\end{array}$ & $\begin{array}{c}\mathrm{N}-\mathrm{NH}_{4} \\
(\mathrm{mg} / \mathrm{l})\end{array}$ & $\begin{array}{c}\mathrm{Al} \\
(\mathrm{mg} / \mathrm{l})\end{array}$ & $\begin{array}{c}\mathrm{Fe} \\
(\mathrm{mg} / \mathrm{l})\end{array}$ & $\begin{array}{c}\mathrm{Mg} \\
(\mathrm{mg} / \mathrm{l})\end{array}$ & $\begin{array}{c}\mathrm{Pb} \\
(\mathrm{mg} / \mathrm{l})\end{array}$ & $\begin{array}{c}\mathrm{Zn} \\
(\mathrm{mg} / \mathrm{l})\end{array}$ \\
\hline Before treatment & 7.8 & 105 & 116 & $<0.05$ & 0.148 & $<0.05$ & $<0.05$ & 0.061 \\
\hline After treatment & 8 & 58 & 11 & $<0.05$ & 9.41 & $<0.05$ & $<0.05$ & $<0.05$ \\
\hline $\begin{array}{c}\text { Emission standard } \\
{[20]}\end{array}$ & $6 \sim 9$ & 70 & 15 & - & - & - & 0.2 & 1.0 \\
\hline
\end{tabular}

After ammonia stripping the concentration of $\mathrm{N}-\mathrm{NH}_{4}$ was found to be about $116 \mathrm{mg} / \mathrm{l}$. Conventional treatment methods could not effectively remove the medium-low concentration of $\mathrm{N}_{-} \mathrm{NH}_{4}$. The FHMAS allows an alternative technique and showed encouraging performance on treating $\mathrm{N}_{-} \mathrm{NH}_{4}$ from the wastewater. The results after treatment by FHMAS were list in Table 4 . When ferric hydroxide $0.15 \mathrm{~mol} / \mathrm{l}$, dosage $3.5 \mathrm{~g} / \mathrm{l}$, and $\mathrm{pH} 8$ contact $30 \mathrm{~min}$ at room temperature, initial $\mathrm{N}-\mathrm{NH}_{4}$ concentration and COD being $116 \mathrm{mg} / \mathrm{l}$ and $105 \mathrm{mg} / \mathrm{l}$; ammonia in actual metallurgical wastewater was reduced to $11 \mathrm{mg} / \mathrm{l}$ and COD to $58 \mathrm{mg} / \mathrm{l}$ for $\mathrm{N}-\mathrm{NH}_{4}$ and COD after treatment by adsorption achieves pollutant concentration limits in solution for a new enterprise in the "Emission Standards of Pollutants from Rare Earths Industry" (GB264512011) [20]. From the adsorption capacity for $\mathrm{N}_{-} \mathrm{NH}_{4}$ $30 \mathrm{mg} / \mathrm{g}$, which was smaller than $32.7 \mathrm{mg} / \mathrm{g}$ at adsorption equilibrium for simulated $\mathrm{N}-\mathrm{NH}_{4}$ solution, it can be seen that some cations and organic constituents in metallurgical wastewater can affect the efficiency of $\mathrm{N}^{-\mathrm{NH}_{4}}$ removal. And the concentration of $\mathrm{Fe}$ ion in wastewater increased because of cation exchange. Therefore, FHMAS was preliminarily feasible for treating $\mathrm{N}_{-} \mathrm{NH}_{4}$ from real wastewater.

\section{Conclusions}

The presented research was carried out to explore a new adsorbent - modified activated sludge - for treating medium-low concentrations of $\mathrm{N}_{-} \mathrm{NH}_{4}$ from wastewater. The experimental results showed that sludge modified by $0.15 \mathrm{~mol} / 1$ ferric hydroxide can greatly improve the removal for $\mathrm{N}_{-} \mathrm{NH}_{4}$. Influencing factors such as $\mathrm{pH}$, concentration of modifier, contact time, and $\mathrm{N}-\mathrm{NH}_{4}$ initial concentration showed the serious influence of $\mathrm{N}^{-\mathrm{NH}_{4}}$ removal. The kinetics study indicated that the sorption process was better described by the pseudo second-order equation than that of Lagergren's first-order equation. An adsorption isotherm study indicated that FHMAS had higher adsorption capacities for $\mathrm{N}^{-\mathrm{NH}_{4}}$ than that of the clinoptilolite. The mechanisms of removal of $\mathrm{N}-\mathrm{NH}_{4}$ by FHMAS were coexistence of adsorption and cation exchange. Metallurgical wastewater containing mediumlow concentrations of $\mathrm{N}^{-\mathrm{NH}_{4}}$ was treated by FHMAS. Initial N-NH$H_{4}$ concentration of $116 \mathrm{mg} / \mathrm{l}$ was reduced to 11 $\mathrm{mg} / \mathrm{l}$ in $30 \mathrm{~min}$ by $3.5 \mathrm{~g} / \mathrm{l}$ FHMAS at $\mathrm{pH} 8$.

\section{Acknowledgements}

The authors gratefully acknowledge financial support from the project of the National Natural Science Fund of China (No. 51568023), the National Science and Technology Pillar Project of the People's Republic of China (No. 2012BAC11B07), and the Jiangxi Provincial Department of Education of China (No. GJJ14419). Additionally, the authors would like to express their sincere appreciation to the anonymous reviewers for their helpful comments and suggestions.

\section{References}

1. CHEN Y., LIU C., NIE J., LUO X., WANG D.Chemical precipitation and biosorption treating landfill leachate to remove ammonium-nitrogen. Clean Techn. Environ. Policy. 17, 1, 2012.

2. CHEN Y., NING P., DENG C. Study on the treatment of ammonia nitrogen wastewater by rare earth absorbent. Environmental Protection of Chemical Industry. 24, 352, 2004.

3. DING S., JIA L., LIU Z. Study on adsorption performance of ammonia nitrogen in simulated tannery wastewater by wheat shell. J. Shaanxi University of Science \& Technology. 30, 8, 2012.

4. HO Y., MCKAY G. Pseudo second-order model for sorption process, Process Biochem. 34, 451, 1999.

5. HOWE K., JOHN C., DAVID W., RHODES R.,GEORGE T. MWH's Water treatment: principles and design $2^{\text {nd }} E d$., Wiley, New Jersey, 2005.

6. JUNG J., CHUNG Y., SHIN H., SON D. Enhanced ammonia nitrogen removal using consistent biological regeneration and ammonium exchange of zeolite in modified SBR process, Water Res. 38, 347, 2004.

7. LIN L., CHA G., JIANG B., LAN C. Use of ammoniacal nitrogen tolerant microalgae in landfill leachate treatment, Waste Manage 27, 1376, 2007.

8. LIU R., SUN L., QU J., LI G. Arsenic removal through adsorption, sand filtration and ultrafiltration: In situ precipitated ferric and manganese binary oxides as adsorbents, Desalination 249 (3), 1233, 2009.

9. LIU Y., LUO G., QUE T., LUO F. Experimentation Study on the Adsorption Capability about the Ammonia Nitrogen from Water Using Clinoptilolite. J. Chongqing University. Jan. 27, 62, 2004.

10. REDDY, D., RAMANA, D., SESHAIAH, K., REDDY, A. Biosorption of $\mathrm{Ni}(\mathrm{II})$ from aqueous phase by Moring aoleifera bark, a low cost biosorbent. Desalination 268, 150, 2011. 
11. ROCHA C., ZAIA D., ALFAYA R., ALFAYA A. Use of rice straw as biosorbent for removal of $\mathrm{Cu}(\mathrm{II}), \mathrm{Zn}(\mathrm{II}), \mathrm{Cd}(\mathrm{II})$ and $\mathrm{Hg}$ (II) ions in industrial effluents. J. Hazard. Mater. 166, 383, 2009.

12. SATHISHA M., MADHANB B., SARAVANANC P., RAOA J., NAIRA B. Dry ice-an eco-friendly alternative for ammonium reduction in leather manufacturing, J. Clean Prod. 54, 289, 2013.

13. SHEN W., LEI G. Study on Ammonia Nitrogen in Municipal Sewage Adsorpted by Actived Coal Serial Kaolin. J. Anhui Agri. Sci. 38 (20), 10845, 2010.

14. SONDERGAARD M., JEPPESEN E. Anthropogenic impacts on lake and stream ecosystems, and approaches to restoration, J. Appl. Ecol. 44, 1089, 2007.

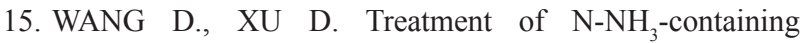
wastewater with Na-base bentonite. J. Chemical Industry \& Engineering. 27, 22, 2006.

16. ZHOU S., WU Y. Improving the prediction of ammonium nitrogen removal through struvite precipitation, Environ. Sci. Pollut. Res. 19, 347, 2012.

17. ZHU L., DING W., FENG L., DAI X., XU X. Characteristics of an aerobic denitrifier that utilizes ammonium and nitrate simultaneously under the oligotrophic niche, Environ. Sci. Pollut. Res. 19, 3185, 2012.

18. YU W., MARKKU P., MIKKO K.. Treatment of High Ammonium-Nitrogen Wastewater from Composting Facilities by Air Stripping and Catalytic Oxidation, Water Air Soil Pollut. 208, 259, 2010.

19. ZHEN W., ZHENG W., LIU G. Experimental Study on Ammonium-nitrogen Adsorption by Artificial Zeolite. Industrial Safety and Environmental Protection 27, 8, 2013.

20. The National Standard of the Peopless Republic of China. Emission Standards of Pollutants from Rare Earths Industry (GB26451-2011), China Environmental Science Press, China, 2011. 